\title{
Prevalence and Patterns of Thyroid Disorders Assessed from Neck Ultrasonography in Western Nepal
}

\author{
Upadhyaya $\mathrm{TL}^{1^{*}}$, Parajuly $\mathbf{S S}^{2}$, Pangeni $\mathbf{R}^{2}$
}

'Dept of Internal Medicine, Gandaki Medical College and Diabetes Thyroid \& Endocrinology Care Center, Pokhara, Nepal ${ }^{2}$ Dept of Radiodiagnosis \& Imaging, Pokhara Academy of Medical Sciences \& Diabetes Thyroid \& Endocrinology Care Center, Pokhara, Nepal

\section{Keywords}

Neck ultrasonography, Thyroid disorders, Western Nepal.

\section{Corresponding author}

*Dr. Tirtha Upadhyaya

Associate Professor

Department of Medicine

Gandaki Medical College \& Teaching Hospital, Pokhara, Nepal

Email: tirtha77@hotmail.com

\section{ABSTRACT}

Background: Thyroid problems are rapidly increasing in the world. Thyroid ultrasonography may be a very simple tool to assess and screen thyroid problems. This retrospective study to assess the prevalence of thyroid disorders from neck ultrasonography in relation to age, gender and disease type was performed in Diabetes Thyroid and Endocrinology Care Center, Pokhara Nepal.

Methods: Five hundred computer saved datas from the Radiology Department of Diabetes Thyroid \& Endocrinology Care Center from April 2017 to April 2018 were collected. Cases were reviewed for age, gender and disease type and statistical analysis was done using SPSS tool.

Results: Out of 500 patients $14 \%$ were males, $86 \%$ were females; age ranged from three days to 86 years. Hasimoto's thyoiditis was commonest problem and very prevalent in women.

Conclusions: Thyroid problems are so common in general population, especially in females. Simple diagnostic tool like neck ultrasonography gives clue to make clinical diagnosis.

\section{INTRODUCTION}

Thyroid related problems are very common these days. Females are affected more than the men as male to female ratio is $1: 10$. Thyroid dysfunction is a major public health problem among the Nepalese population too ${ }^{1}$. It has been estimated that $0.2 \%$ of the deaths in Nepal result from endocrine disorders, among which thyroid problems has been a major cause ${ }^{2}$. In earlier days iodine deficiency was the major cause for hypothyroidism in Nepal but now it is not the cause as autoimmunity is the major cause. The thyroid disorders may be due to congenital factors, a genetic predisposition, inadequate levels of dietary iodine intake, pregnancy, radiotherapy, viral infections, surgery, underlying diseases such as infiltrative disorders, or even autoimmunity ${ }^{3-5}$. Any age group can be affected by thyroid problems. As thyroid disorders are major problems in present scenario, we tried to find the simple and cost effective tool to detect and treat thyroid disorders in underdeveloped country like Nepal.

\section{MATERIALS \& METHODS}

\section{The Study Design}

This is a hospital based study conducted in the Department of Radiology of Diabetes Thyroid \& Endocrinology Care Center, Pokhara, Nepal. In this retrospective study, the subjects who visited Diabetes Thyroid \& Endocrinology Care Center from April 1, 2017 to April 1, 2018 were enrolled. These patients had some degree of clinical 
suspicion of thyroid disorders and some of them even had performed the thyroid function test. The subjects with no clinical suspicion of thyroid disorders were excluded from the study. The variables which were collected were age, gender and the type of thyroid disorders.

\section{RESULTS}

Out of 500 patients $14 \%$ were males, $86 \%$ were females, age ranged from three days to 86 years. Hasimoto's thyroiditis was commonest problem and very prevalent in women.

Fig 1: Male to female ratio

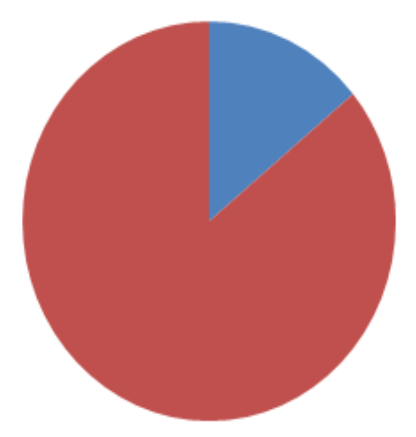

\section{male}

female

-

Fig 2: Age

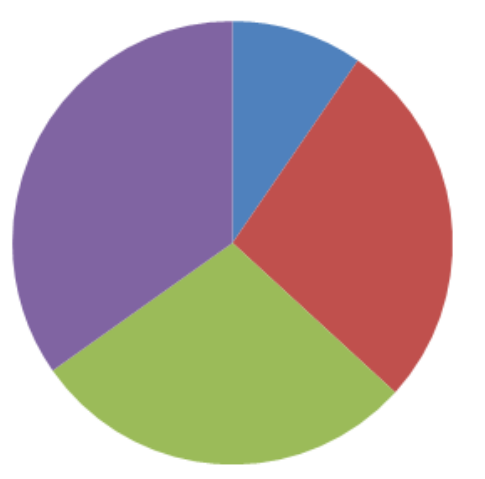

$=0-20$

- 21-40

- $41-60$

a 61 above

Fig 3: Disease type

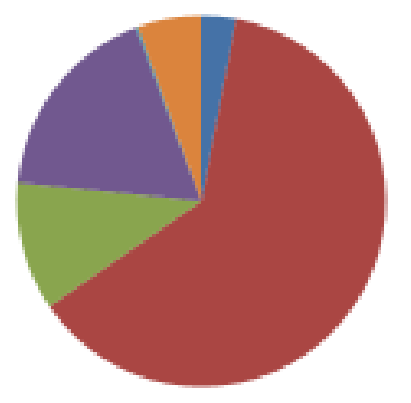

\section{DISCUSSION}

Thyroid dysfunction is a major public health problem among the Nepalese population ${ }^{1}$. It has been estimated that $0.2 \%$ of the deaths in Nepal result from endocrine disorders, among which Iodine deficiency has been a major cause ${ }^{2}$. But nowadays thyroid problems are shifting from iodine deficiency to autoimmue thyroid disorders in Nepal. The thyroid disorders may be due to congenital factors, a genetic predisposition, inadequate levels of dietary iodine intake, pregnancy, radiotherapy, viral infections, surgery, underlying diseases such as infiltrative disorders, or autoimmunity ${ }^{3-5}$.

In this study, females showed a higher prevalence of thyroid dysfunction than males as $86 \%$ of the populations were female. This might be because of females are very prone to autoimmune disorders than males as many other studies also show this pattern ${ }^{6}$. However, a contrasting result was observed by Baral $\mathrm{N}$ et al, where they reported equal prevalence of thyroid dysfunction in males and females ${ }^{1}$. It had been reported earlier that there was a $20 \%$ overall prevalence of thyroid dysfunction in Eastern Nepal in subjects who were above 20 years of age ${ }^{7}$.

Neck ultrasonography may be the simple tool to access thyroid problem in economically poor country like Nepal. Most of thyroid diseases are benign and just need medical treatment and follow up and very few may need surgical intervention. Clinical and laboratory assessment is not sufficient for identification of nature of thyroid diseases. So imaging is mandatory for these cases $^{9}$. Ultrasonography is the most widely used application for diagnosis of thyroid diseases. It is safe, cheap, time saving and has high sensitivity and specificity for thyroid lesion characterization $^{8}$. It can characterize most of thyroid lesions and detect small sized nodules less than $3 \mathrm{~mm}$ and can evaluate the other nearby neck structures like lymph nodes, carotid arteries, jugular veins, major salivary glands.

There is characteristic ultrasonography finding of different thyroid disorders ${ }^{8}$. Normal thyroid have homogenous bright gland; diffuse toxic goiter (Graves disease) have enlarged gland with homogenous to coarse texture and high vascularity, Hashimoto's thyroiditis have heterogenous echotexture with increased vascularity, multinodular nontoxic goiter have enlarged glands with large bright nodules and average vascularity, subacute thyroiditis have multiple patchy hypoechoic areas with 
normal vascularity. Malignant nodules appear hypoechoic with intranodular flow with punctuate calcifications. Colloid cysts appear anechoic with few hyperechoic foci with comet tail artifacts due to thyroglobulin chains. By using simple ultrasonography major thyroid problems can be detected and treated.

\section{CONCLUSIONS}

Thyroid problems are very common in general populations, especially in females and in economically underprivileged country like Nepal. Simple diagnostic tool like neck ultrasonography give clue to make clinical diagnosis. It is safe, cheap, time saving and has high sensitivity and specificity for thyroid lesion characterization.

\section{REFERENCES}

1. Baral N, Lamsal M, Koner BC, Koirala S. Thyroid dysfunction in Eastern Nepal. Southeast Asian J Trop Med Public Health. 2002; 33: 638-41. [PubMed]

2. Ganie MA, Zargar AH. Scenario of endocrinology in South Asia. Indian J Endocrinol Metabol. 2007; 11: 1-2.

3. Vanderpump MP, Tunbridge WM. Epidemiology and prevention of clinical and subclinical hypothyroidism. Thyroid. 2002; 12: 839-47. [PubMed]

4. Wiersinga WM. Subclinical hypothyroidism and hyperthyroidism: Prevalence and clinical relevance. Neth J Med. 1995; 46: 197-204. [PubMed]

5. Brownlie BE, Wells JE. The epidemiology of thyrotoxicosis in New Zealand: incidence and geographical distribution in North Canterbury, 1983-1985. Clin Endocrinology. 1990; 33: 249-59. [PubMed]

6. Quintero OL, Amador-Patarroyo MJ, MontoyaOrtiz G, et al. Autoimmune disease and gender: Plausible mechanisms for the female predominance of autoimmunity. J Autoimmun. 2012; 38: J109 - 19. [PubMed][CrossRef]
7. Shrestha S, Das BKL, Baral N, et al. Association of metabolic syndrome and its component with thyroid dysfunction in females. Int J Diab Dev Ctries. 2007; 27: 24-26.

8. Saad Rezk Abdel, et al. Role of ultrasound in evaluation of thyroid diseases. Al-Azhar Assiut Medical Journal. 2015; 13(2): 173-180.

9. Screaton NJ, Berman LH, Grant JW. US guided coreneedle biopsy of the thyroid gland. Radiology. 2003; 226(3): 827-832. 